\title{
Pollination Biology of the Muscadine Grape
}

\author{
Blair Sampson ${ }^{1}$, Steve Noffsinger ${ }^{2}$, Creighton Gupton ${ }^{2}$, and \\ James Magee ${ }^{3}$ \\ U.S. Department of Agriculture, Agricultural Research Service, Small Fruit \\ Research Station, Poplarville, MS 39470
}

Additional index words. Vitis rotundifolia, bees, entomophily, anemophily, fruit set, seed set, parthenocarpy

\begin{abstract}
Fruit set in the muscadine grape (Vitis rotundifolia Michx.) depended on insect cross-pollination, although flowers were well adapted for selfing. Pollinizer cultivars produced about half of their optimal fruit set when selfed, but cross-pollination was needed to reach an optimal fruit set of $33.7 \%$. Eighty-one percent of the overall fruit set in pistillate vines was attributed to insect cross-pollination; wind played only a small role. Diminished fruit set and fewer seeds per berry occurred in cultivars receiving no effective cross-pollination. Components of fruit quality were not profoundly affected by the pollination treatments, although seed set and berry weight in pistillate cultivars was lower in the absence of cross-pollination. Parthenocarpy was rare, except in 'Fry Seedless'. Muscadine production throughout the southeastern United States depends on cross-pollination by indigenous insects, particularly bees. To ensure consistently high yields, bees must have safe access to flowers and their nesting sites must be preserved.
\end{abstract}

The extent to which selfing, wind, and insects contribute to fruit set and quality in muscadines and other grape species is poorly understood. After two centuries of cultivation, selfing was made possible for the naturally dioecious muscadine by the introduction of self-compatible, hermaphroditic cultivars. Selfing ensures some level of fruit set in grapes and can occur before buds open (cleistogamy) or later as a tensile cap or calyptra abscises (Mullins et al., 1992). However, reproduction and productivity in selfpollinating plants are typically enhanced by cross-pollination (Kalifman, 1977; Kearns and Inouye, 1993; McGregor, 1976).

Muscadine grape flowers are adapted for insect pollination and can be wind-pollinated (Faegri and van der Pijl, 1971), but the crosspollination agent most responsible for fruit set must be identified before recommending new pollination practices. Wind is thought to be the most important agent (Mullins et al., 1992), but is probably effective only when insect pollinators are scarce (McGregor, 1976). Muscadine pollen grains are sufficiently small $(30-60 \mu \mathrm{m}$ in diameter) to remain buoyant in air (Gupton,

Received for publication 28 Dec. 1999. Accepted for publication 19 May 2000. We thank Cynthia DeFouquette, Danita Lewis, Brandy Powell, Sara May, Ronnie Mills, Robin Nix, and Nicholas Rutledge for their invaluable field and lab assistance. We are grateful to John Braswell and John Clark for their knowledgeable review of the manuscript. The cost of publishing this paper was defrayed in part by the payment of page charges. Under postal regulations, this paper therefore must be hereby marked advertisement solely to indicate this fact.

${ }^{1}$ Research Entomologist. To whom requests for reprints should be addressed. E-mail address: bsampson@ars.usda.gov

${ }^{2}$ Research Geneticist.

${ }^{3}$ Research Horticulturist. unpublished data; McGregor, 1976) and even in trace amounts are noticeably allergenic beyond the boundaries of the vineyard (Feo Brito et al., 1999). Most airborne pollen grains settle on the dense foliage surrounding grape inflorescences. In addition, pistils from muscadine flowers differ from those of many anemophilous plants in that they lack enlarged stigmata for more efficiently intercepting airborne pollen.

Insects were not considered to be important pollinators of grapes because of their erratic densities in flowering vineyards and the self-fruitful character of many of the cultivars (Free, 1970; McGregor, 1976; Tkachenko, 1977), but pistillate cultivars do require crosspollination. Muscadine flowers offer nectar as a reward to insect pollinators (McGregor, 1976); pollen as food, or pollen may be thrust upon them as calyptras eject. The ability of bees to pollinate muscadine flowers has been associated with their abundance and particular pollen-collecting behaviors. For instance, halictid bees are more numerous on muscadine flowers and are more apt to deposit the drier, flaky pollen they collect on the pistils. Moistened pollen pellets formed by less abundant honeybee and bumblebee workers are less likely to break apart and land on receptive pistils (Armstrong, 1936; Dearing, 1938; Detjen, 1917). However, commercial honeybees would be sufficiently abundant to pollinate muscadine flowers when native bees are in short supply (McGregor, 1976). Soldatov (1976) estimated that honeybees and wild native bees contributed $29 \%$ to the total berry yield per hectare. In addition, the bodies of flies and wasps as well as of herbivorous beetles can be dusted with grape pollen and may also contribute to pollination (Armstrong, 1936; Dearing, 1938; Detjen, 1917).

Recommendations presently do not specify exact densities of bees needed for pollinating muscadine grapevines or acknowledge the full contribution insects make to muscadine production. Therefore, we designed pollination experiments to provide information on muscadine pollination biology and to assess the importance of insect pollination. Experiments focussed on: 1) measuring pollen viability of pollinizer (hermaphroditic) vines; 2) the timing of pistil receptivity to determine if muscadine flowers are capable of limited cleistogamy; and 3) quantifying the relative contributions of self-, wind-, and insect-pollination to fruit set and development.

\section{Materials and Methods}

Pollen viability and timing of stigmatic receptivity. Pollen extraction for in vitro viability testing began in the field by gathering inflorescences containing dehisced anthers. Flowers were transported on ice to the laboratory where pollen was dispensed from the anthers onto a glass slide. A fresh preparation of acetocarmine stain was added to the well on the depression slide. Fifteen minutes at 21 ${ }^{\circ} \mathrm{C}$ was allowed for pollen grains to absorb the stain, and those grains showing obvious staining of the cytoplasm were judged viable. Pollen viability was calculated as the number of stained pollen grains in a pooled pollen count from five random samples. A total of 90 muscadine pollen samples were collected from the 18 hermaphroditic cultivars (Fig. 1). The chi-square test (PROC CATMOD, SAS Institute, 1985) was used to detect differences in the proportions of viable and nonviable pollen grains among the cultivars. Pistillate flowers did not produce sufficient pollen for viability testing.

The timing of floral receptivity was quantified by measuring the percentage of pistils showing signs of peroxidase activity, using peroxidase indicator (Sigma, St. Louis; Kearns and Inouye, 1993) before and after the calyptra ejected. Eight to ten stigmata were tested from the cultivars Black Beauty, Carlos, Doreen, Fry, Fry Seedless, Higgins, Sweet Jenny, Supreme, and Summit (total = 81 pistils). A $2 \times 2$ contingency table analysis (PROC FREQ, SAS Institite, 1985) tested the effect of flower maturity (before and after the calyptra ejected) on the proportion of stigmata exhibiting peroxidase activity in vitro.

Effects of insect-, wind-, and self-pollination on fruit set and fruit attributes. Hermaphroditic vines are considered to be more self-fertile. Testing this hypothesis involved comparing the effects of self- vs. cross-pollination. Cross-pollination on five panicles per vine was prevented by enclosing them in large brown paper bags. As a control, five more panicles on each vine were exposed to natural pollination agents, including self-pollination, wind and insects. We minimized future damage to the bags caused by growing shoots by pinching off actively growing meristems before bagging. The open ends of the paper exclusion bags were closed and secured to rigid spurs or cordons with twine after bud counts on 26-28 Apr. 1999. Selecting only 


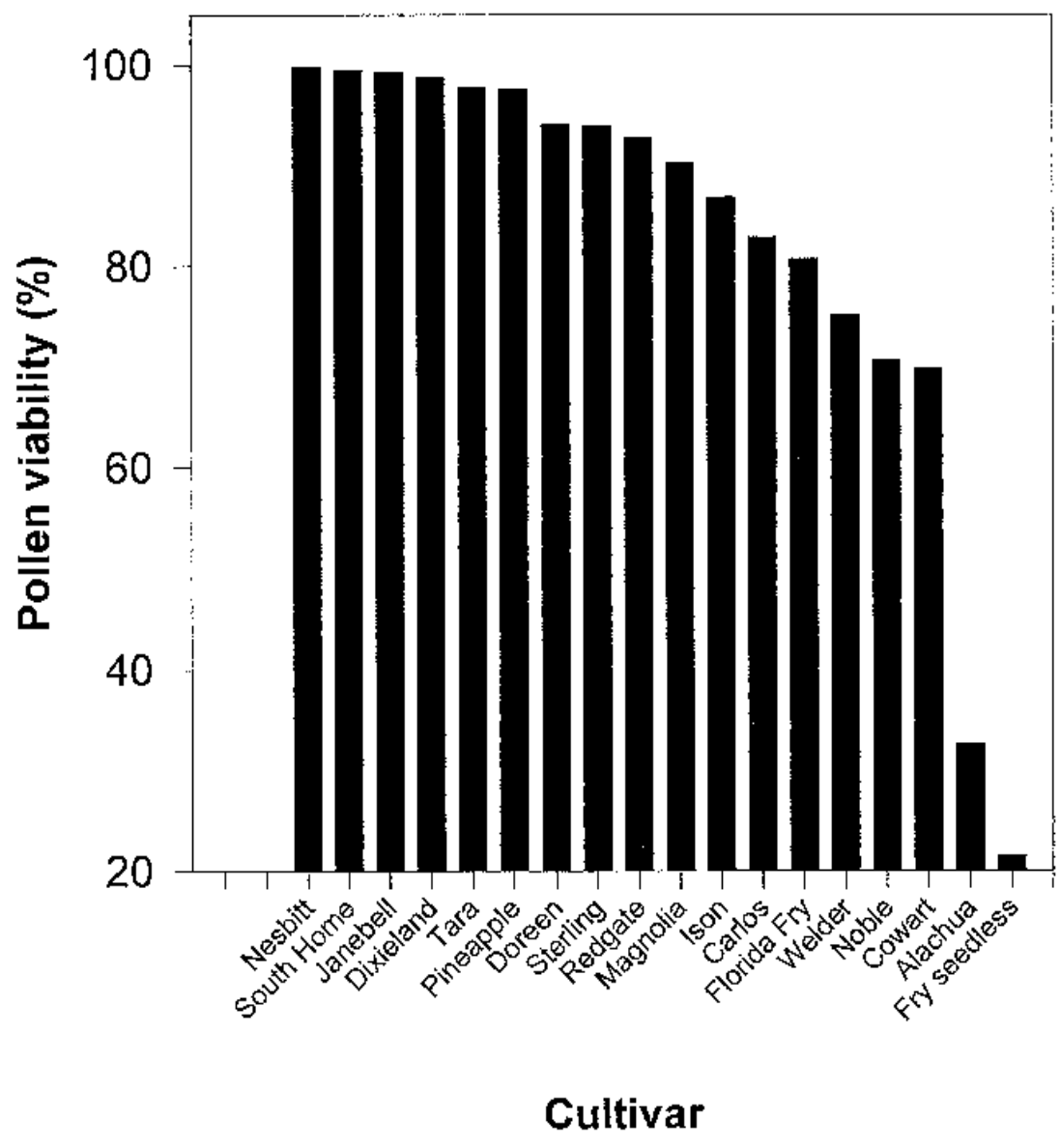

Fig. 1. Variability in pollen viability expressed by 18 hermaphroditic muscadine grape cultivars.

panicles from the two east-facing cordons from every plant minimized variation in percentage of fruit set attributed to microclimatic variability. The hermaphroditic cultivars were 'Doreen', 'Florida Fry', 'Fry Seedless', 'Magnolia', 'Nesbitt', and 'Tara', and vines were trained on Geneva double-curtain trellises. Four plants per cultivar were randomly assigned to each of four randomized complete-blocks at a research vineyard in McNeill, Miss. (total N = 96 hermaphroditic vines). This arrangement permitted comparisons between treatments and cultivars.

Similar bagging procedures were followed for panicles of pistillate vines. The pistillate cultivars Black Beauty, Fry, Hunt, Sugargate, Summit, and Sweet Jenny were used only to assess the contributions of wind, insects, and parthenocarpy because female vines are largely self-infertile. We were unable to totally segregate the effects of insect pollinators from wind effects. However, for each vine, we used five finely woven mesh bags with drawstrings (M and MEnterprises, McNeill, Miss.) to exclude insects and allow only airborne pollen to pass. Five brown paper bags attached to the cordons prevented cross pollination of flowers on five more panicles. Five additional open-pollinated panicles per pistillate vine were used as a control. Four vines of each pistillate cultivar were also arranged in randomized complete blocks and were assigned to the same blocks as hermaphroditic vines. This allowed us to com- pare differences in fruit set and fruit characteristics between hermaphroditic and pistillate vines and treatments, at least for panicles that were open- and self-pollinated.

Fruit were harvested on 9-10 Aug. 1999 and again on 17 Aug. for some of the latermaturing fruit. Fruit set was calculated as the percentage of flowers that set ripe and fullsized ripening fruit for each tagged panicle. Many panicles yielded no fruit when we prevented insect and wind pollination. Therefore, normality in the distribution of fruit set was improved by using the angular transformation: $\theta=\arcsin [\operatorname{sqrt}(\%$ fruit set/100)] (Sokal and Rohlf, 1969).

Fruit were refrigerated at $2{ }^{\circ} \mathrm{C}$ inside polyethylene bags. Berry analysis began $24 \mathrm{~h}$ after harvest and took $2 \mathrm{~d}$ to complete. Each berry was weighed and then sliced longitudinally to remove seeds for counting (seed set). The percentage of soluble solids ( ${ }^{\circ} \mathrm{Brix}$ ) for the juice squeezed from each berry was measured once with a $0-50{ }^{\circ}$ Brix low-volume field refractometer (Bellingham and Stanley, Norcross, Ga.) at $20^{\circ} \mathrm{C}$.

The effects of the different modes of pollination (open pollination, wind pollination, no insect or wind pollination), cultivars, and their interactions on each of the four dependent variables (fruit set, fruit weight, seed set, and percentage of soluble solids) were partitioned using a two-way analysis of variance [(ANOVA) in PROC GLM, SAS Institute,
1985]. Sequential sums of squares and residual mean square error were used for calculating F-ratios and deriving probabilities for the main effects and interaction terms in the ANOVA models. Mean differences were classified using Tukey's honestly significant difference (HSD) test at $P \leq 0.05$.

\section{Results}

Hermaphroditic cultivars were very pollen-fertile, with viability ranging from $69.8 \%$ to $99.8 \%$ (Fig. 1). Reduced levels of in vitro pollen viability $(<33 \%)$ for 'Alachua' and 'Fry Seedless' (Fig. 1) demonstrated that the hermaphroditic flowers of these two cultivars function more as females $\left(\chi^{2}=417.3, \mathrm{df}=1\right.$, $17, P \leq 0.001)$. Perfect flowers of muscadine grapes readily selfed; cleistogamy is a possible mechanism for pollen transfer because $22 \%$ of pistils exhibited peroxidase activity, demonstrating stigmata were receptive before buds opened $\left(\chi^{2}=32.545, \mathrm{df}=1,80, P \leq\right.$ $0.001)$. In the remaining $78 \%$ of the detached pistils, stigmata only became receptive after the calyptra ejected to expose flowers to insect- and wind-borne pollen.

Cross-pollination was vital to berry set. Two-thirds of fruit set for all 12 cultivars was attributed to a combination of insect and wind cross-pollination. Overall, open-pollinated flowers set $33.7 \%$ fruit, whereas protected flowers set only $11.6 \%(\mathrm{~F}=109.64$, df $=1$, $480, P \leq 0.0001)$. A significant interaction between flower type (hermaphroditic and pistillate) and two pollination treatments (openpollination, self-pollination) demonstrated that pistillate cultivars set a larger percentage of fruit than did hermaphrodites when open-pollinated, but a lower percentage when bags excluded wind and insects $(\mathrm{F}=24.70, \mathrm{df}=1$, $480, P \leq 0.0001$, Fig. 2). Fruit set for bagged hermaphroditic flowers was close to that of open-pollinated flowers (Fig. 2), indicating a negligible adverse effect of bagging. We assumed that adverse bag effects were also minimal for the pistillate cultivars, and that differences in fruit set were principally due to pollination treatments.

Self-fertility appeared to alter the fruit set responses for both hermaphroditic and pistillate flowers when we excluded all cross-pollination agents. Extreme examples were hermaphroditic 'Fry Seedless' and pistillate 'Black Beauty', which produced no fruit when selfed. Cross-pollination by wind and insects increased fruit set $47.5 \%$ in hermaphroditic vines and $91.3 \%$ in pistillate ones (Fig. 2). Insect pollination contributed most $(81.2 \%)$ to the overall fruit set for pistillate vines. Wind pollination accounted for an average of $10.1 \%$, and selfpollination $8.7 \%$, to overall fruit set of the pistillate cultivars (Fig. 2B). Pistillate vines set fruit poorly in the absence of efficient cross-pollination (Fig. 2B). A significant pollination mode by cultivar interaction showed that the hermaphroditic cultivar Tara produced more fruit when flowers were selfed, whereas the other hermaphroditic cultivars experienced lower fruit sets (Fig. 2A). Significant treatment by cultivar interaction for pistillate vines 
indicated that 'Sweet Jenny' was more selffruitful and that wind appeared to be the principal pollen vector (Fig. 2B).

Cross-pollination resulted in two to four seeds per fruit vs. one to four seeds for selfing (Table 1, Fig. 3). The hermaphroditic cultivars all produced fewer seeds when selfed (Fig. 3A). However, a significant treatment by cultivar interaction showed a more profound reduction in seed set for pistillate 'Sweet Jenny' and no fruit or seeds for 'Black Beauty' after flowers were selfed (Table 1, Fig. 3B). All cultivars, with the exception of 'Fry Seedless', rarely produced seedless fruits (parthenocarpy) in the absence of cross-pollination (Table 1, Fig. 3). 'Fry Seedless' produced very small, consistently seedless fruit (Fig. 3A).

Fruit weight and soluble solids were not affected by cross-pollination in hermaphro- ditic cultivars (Table 1, Figs. 4A and 5A), but pistillate vines yielded larger fruit when open- pollinated (Table 1, Fig. 4B). A significant treatment by cultivar interaction suggested that the pistillate cultivars Black Beauty, Hunt, and Sweet Jenny were particularly sensitive to fruit size reduction due to a lack of cross-pollination (Fig. 4B). The pistillate cultivars Sweet Jenny, Sugargate, Summit, and Black Beauty on pistillate vines contained higher soluble solids when crosspollination was prevented (Table 1, Fig. 5B).

\section{Discussion}

The percentage of viable pollen differed among the 18 muscadine cultivars and this may have impacted their pollenizing efficiency. 'Alachua' and 'Fry Seedless' pollen

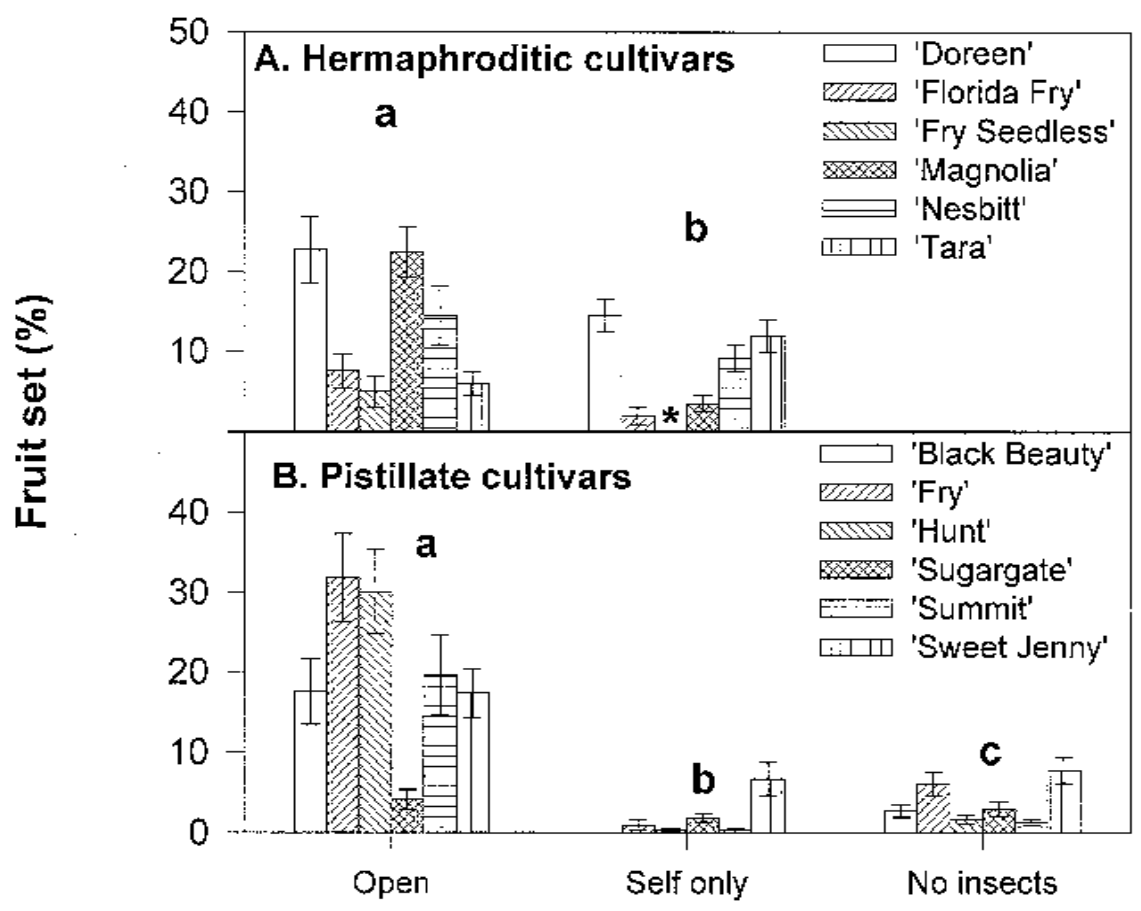

Fig. 2. Influence of open-pollination, self-pollination (self only), and wind-plus self-pollination (no insects) on muscadine fruit set. Bars represent mean fruit set $\pm 1 \mathrm{sE}$ for each cultivar designated in the legend. Mean separation for pollination treatments denoted by Tukey's HSD test at $P \leq 0.05$. Pollination mode $\times$ cultivar interactions for both hermaphroditic and pistillate vines significant at $P \leq 0.0001$. The asterisk in (A) indicates that 'Fry Seedless' produced no fruit when selfed.

viability was noticeably low and these two genotypes would function poorly as pollinizer plants. In a commercial vineyard, 'Fry Seedless' would function as a pistillate vine, and require pollination from other cultivars to set fruit. 'Fry Seedless' also produced $100 \%$ seedless fruit, although some of its pollen remained viable $(21 \%)$. 'Fry Seedless' can produce, very rarely, a larger-sized seeded fruit. A combination of self and crosspollination did not enhance berry size in 'Fry Seedless' or in any other self-fertile cultivar. Because of its unusually small fruit size, 'Fry Seedless' requires routine applications of gibberellic acid $\left(\mathrm{GA}_{3}\right)$.

Self-sterility in grapes is largely affected by pollen viability and not by genetic incompatibility (Free, 1970). Likewise, the efficiency of cross-pollination could be enhanced by greater pollen viability. We observed substantial variability in pollen viability for muscadine cultivars, which partly explains how fruit set in pistillate vines can vary with pollenizer cultivar (NeSmith, 1999). Thus, pollen viability affects muscadine fruit set and ought to be one of many traits considered when interplanting cultivars.

We have some preliminary evidence for cleistogamy in muscadines, a form of selfpollination that occurs in other grape species (Mullins et al., 1992). Some flowers had the potential to self-pollinate before opening because pistils showed signs of receptivity (peroxidase activity) before the calyptra ejected. Even cleistogamy does not preclude crosspollination for muscadine flowers. A majority $(78 \%)$ of pistils became receptive after the calyptra fell off, allowing flowers to be both self- and cross-pollinated.

Selfing contributed much more to fruit set in hermaphroditic than in pistillate cultivars. Over half the fruit set of hermaphroditic vines, but only $9 \%$ of that of pistillate vines, was attributable to self-pollination. Self-pollination of hermaphroditic cultivars reduced fruit set and slightly reduced seed set, but did not affect berry weight or percentage of soluble solids. In contrast, fruit set in pistillate vines fell $\approx 90 \%$ when flowers were not cross-pollinated. Variation in fruit set and seed set was greatest when flowers were enclosed in paper bags, indicating that some hermaphroditic and pistillate cultivars can produce more fruit

Table 1. Analysis of variance of the effects of pollination mode and cultivar on percentage of fruit set, seeds per berry, fruit weight, and percentage of soluble solids of muscadine grape.

\begin{tabular}{|c|c|c|c|c|c|c|c|c|c|c|c|c|}
\hline \multirow[b]{2}{*}{ Source } & \multicolumn{3}{|c|}{ Fruit set (\%) } & \multicolumn{3}{|c|}{ Seeds per berry } & \multicolumn{3}{|c|}{ Fruit wt $(\mathrm{g})$} & \multicolumn{3}{|c|}{ Soluble solids (\%) } \\
\hline & $\mathrm{df}$ & $\mathrm{F}$ & $P$ & df & $\mathrm{F}$ & $P$ & $\mathrm{df}$ & $\mathrm{F}$ & $P$ & $\mathrm{df}$ & $\mathrm{F}$ & $P$ \\
\hline \multicolumn{13}{|c|}{ Hermaphroditic genotypes } \\
\hline Model & 11 & 14.66 & 0.0001 & 10 & 36.85 & 0.0001 & 10 & 61.00 & 0.0001 & 10 & 26.92 & 0.0001 \\
\hline Pollination mode & 1 & 24.48 & 0.0001 & 1 & 7.25 & 0.0075 & 1 & 2.16 & 0.1429 & 1 & 2.33 & 0.1274 \\
\hline Cultivar & 5 & 20.10 & 0.0001 & 5 & 72.49 & 0.0001 & 5 & 119.66 & 0.0001 & 5 & 47.31 & 0.0001 \\
\hline Pollination $\times$ cultivar & 5 & 7.21 & 0.0001 & 4 & 1.85 & 0.1191 & 4 & 2.38 & 0.0518 & 4 & 7.60 & 0.0001 \\
\hline Error & 227 & NA & & 343 & NA & & 337 & NA & & 336 & NA & \\
\hline \multicolumn{13}{|c|}{ Pistillate genotypes } \\
\hline Model & 17 & 15.01 & 0.0001 & 16 & 6.56 & 0.0001 & 16 & 22.00 & 0.0001 & 16 & 9.78 & 0.0001 \\
\hline Pollination mode & 2 & 90.10 & 0.0001 & 2 & 12.85 & 0.0001 & 2 & 43.35 & 0.0001 & 2 & 9.89 & 0.0001 \\
\hline Cultivar & 5 & 6.31 & 0.0001 & 5 & 5.71 & 0.0001 & 5 & 6.20 & 0.0001 & 5 & 6.09 & 0.0001 \\
\hline Pollination $\times$ cultivar & 10 & 4.61 & 0.0001 & 9 & 2.02 & 0.0361 & 9 & 4.67 & 0.0001 & 9 & 2.53 & 0.0078 \\
\hline Error & 347 & $\mathrm{NA}$ & & 391 & NA & & 388 & NA & & 387 & NA & \\
\hline
\end{tabular}




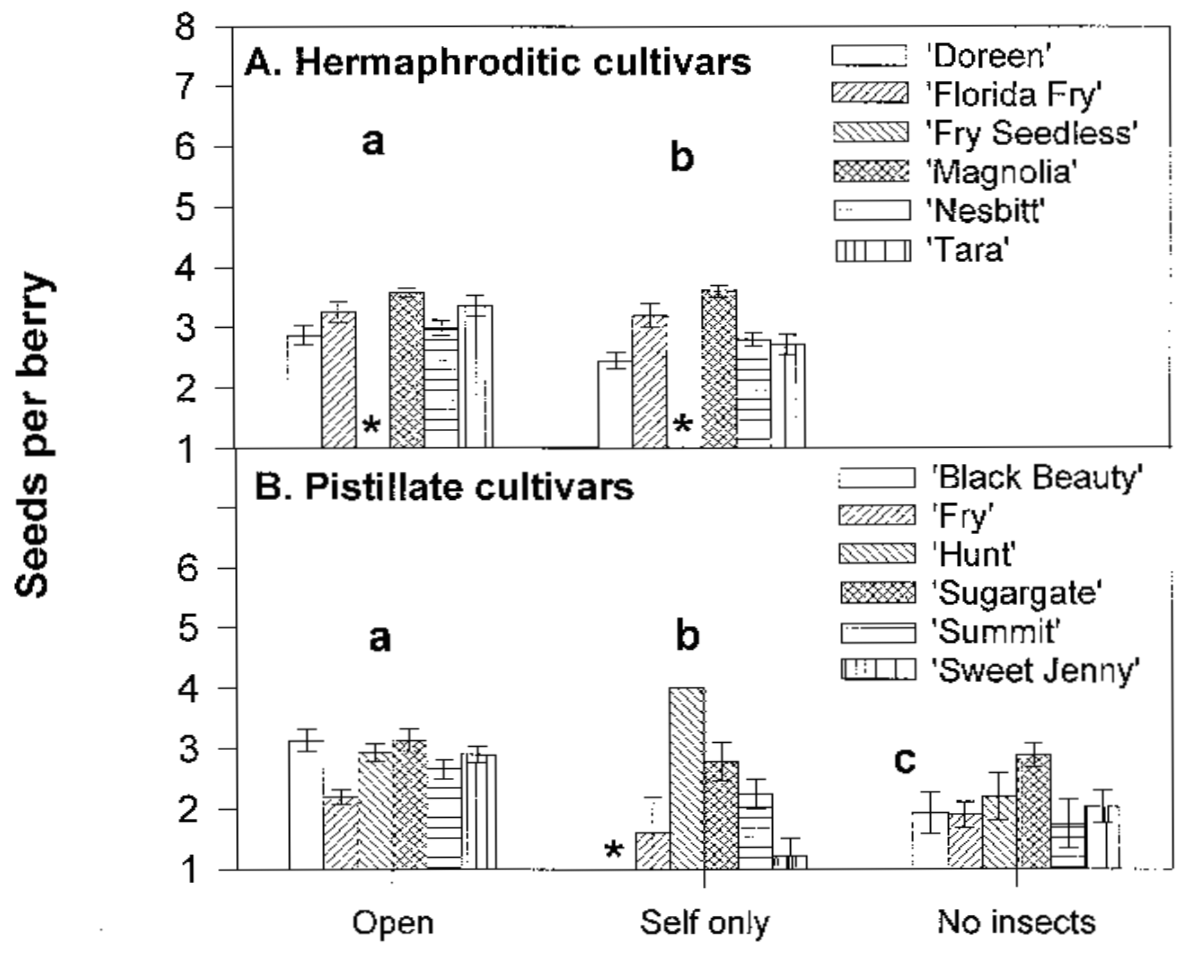

Fig. 3. Effects of open-pollination, self-pollination (self only), and wind- plus self-pollination (no insects) on seed number in muscadine grape. Bars represent mean number of seeds \pm 1 SE per fruit for each of the cultivars. Mean separation for pollination treatments by Tukey's HSD test at $P \leq 0.05$. Pollination mode $\times$ cultivar interaction was significant only for hermaphroditic vines $(P=0.036)$. The asterisks in (A) indicate that all 'Fry Seedless' berries were seedless when open-pollinated or no berries were produced when flowers were selfed. The asterisk shown in (B) indicates that 'Black Beauty' flowers produced no fruit when selfed. All other cultivars produced some seeded fruits.

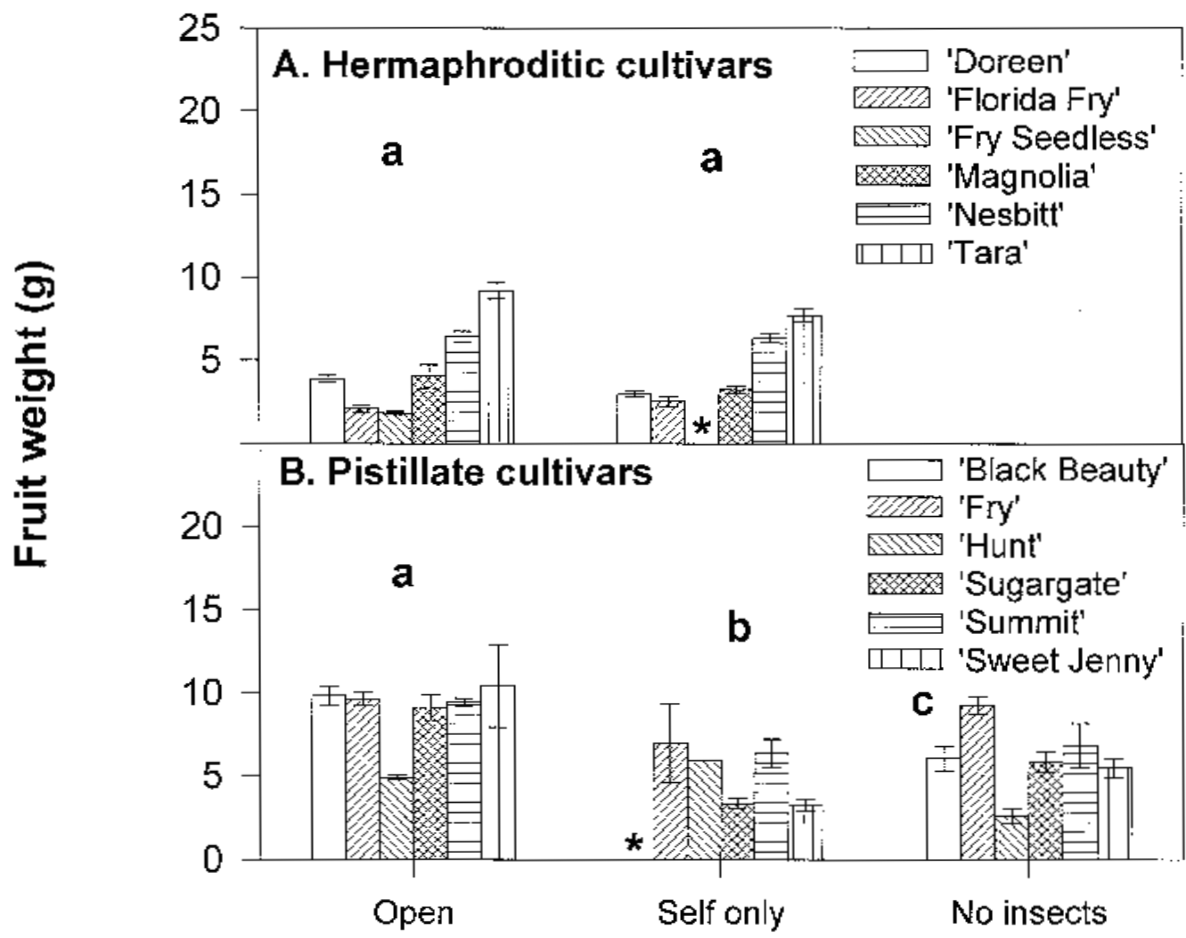

Fig. 4. Effects of open-pollination, self-pollination (self only), and wind- plus self-pollination (no insects) on fruit weight (g/berry) of muscadine grapes. Bars represent mean fruit weight $\pm 1 \mathrm{sE}$ for each cultivar. Mean separation for pollination treatments by Tukey's HSD test at $P \leq 0.05$. Pollination mode $\times$ cultivar interaction for hermaphroditic vines only was significant at $P \leq 0.0001$. The asterisks indicate that no 'Fry Seedless' or 'Black Beauty' flowers produced fruit when selfed. All other cultivars produced some seeded fruits. or seeds than others without cross-pollination. Selfing especially enhanced fruit set for hermaphroditic 'Tara'. Berries produced by pistillate vines receiving no effective crosspollination were smaller, with fewer seeds, especially in 'Sweet Jenny', and a higher percentage of soluble solids; fruit size was proportional to seed number and inversely related to soluble solids content.

Clearly, cross-pollination is vital for gene transmission for natural populations of $V$. rotundifolia and for fruit production in commercial cultivars. Pistillate vines set more fruit than hermaphrodites when crosspollinated, and are normally planted at greater densities in muscadine vineyards. This undoubtedly increases the reliance on cross-pollination for adequate fruit load. Without cross-pollination, pistillate vines produce fewer fruit than do hermaphroditic vines. Almost half the fruit set by hermaphroditic and $91 \%$ fruit set by pistillate vines was the result of cross-pollination by wind and insects. For pistillate cultivars, insect crosspollination enhanced fruit set about four times more than did self-pollination. Insect pollination accounted for $\approx 81 \%$ of the fruit set in pistillate vines with $\approx 10 \%$ attributable to wind-borne pollen. The reduced efficiency of wind pollination of flowers is due to a lack of adaptation for producing and capturing sufficient amounts of suspended pollen. For the majority of purely anemophilous plants, very dense inflorescences release copious amounts of dry, buoyant pollen into the air stream. Flowers that receive this pollen typically have enlarged or feathery stigmata that improve stigmatic loading. Muscadine inflorescences are concealed by foliage and the flowers are equipped for rewarding insect visitors with pollen and nectar. Muscadine floral buds also open when air temperature exceeds $16{ }^{\circ} \mathrm{C}$, a thermal threshold also favorable for insect flight (Pratt, 1971; Winkler, 1974). The one exception to this rule was 'Sweet Jenny'; primarily wind and not insect cross-pollination improved this cultivar's fruit set.

Bees are the principal pollinators of muscadine flowers. We do not know if the $33.7 \%$ fruit set for open-pollinated flowers was optimal in our small experimental vineyard or if it can be improved with supplemental honeybee pollination or increased native bee populations. Fruit set was probably near optimum, as the normal fruit set range for muscadine grape is from $20 \%$ to $30 \%$. This $10 \%$ variability in fruit set may be partially due to fluctuating densities of insect pollinators. Tkanchenko (1977) summarized observations that suggested that grape flowers are not preferred floral hosts for many bee species and that competing blooms readily draw bees away from flowering grape vineyards in southern Ukraine. However, the smaller muscadine flowers were excellent pollen sources for smaller bee species, especially sweat bees in the family Halictidae (Sampson, data not shown). Indigenous bee species are potentially important pollinators of muscadine 


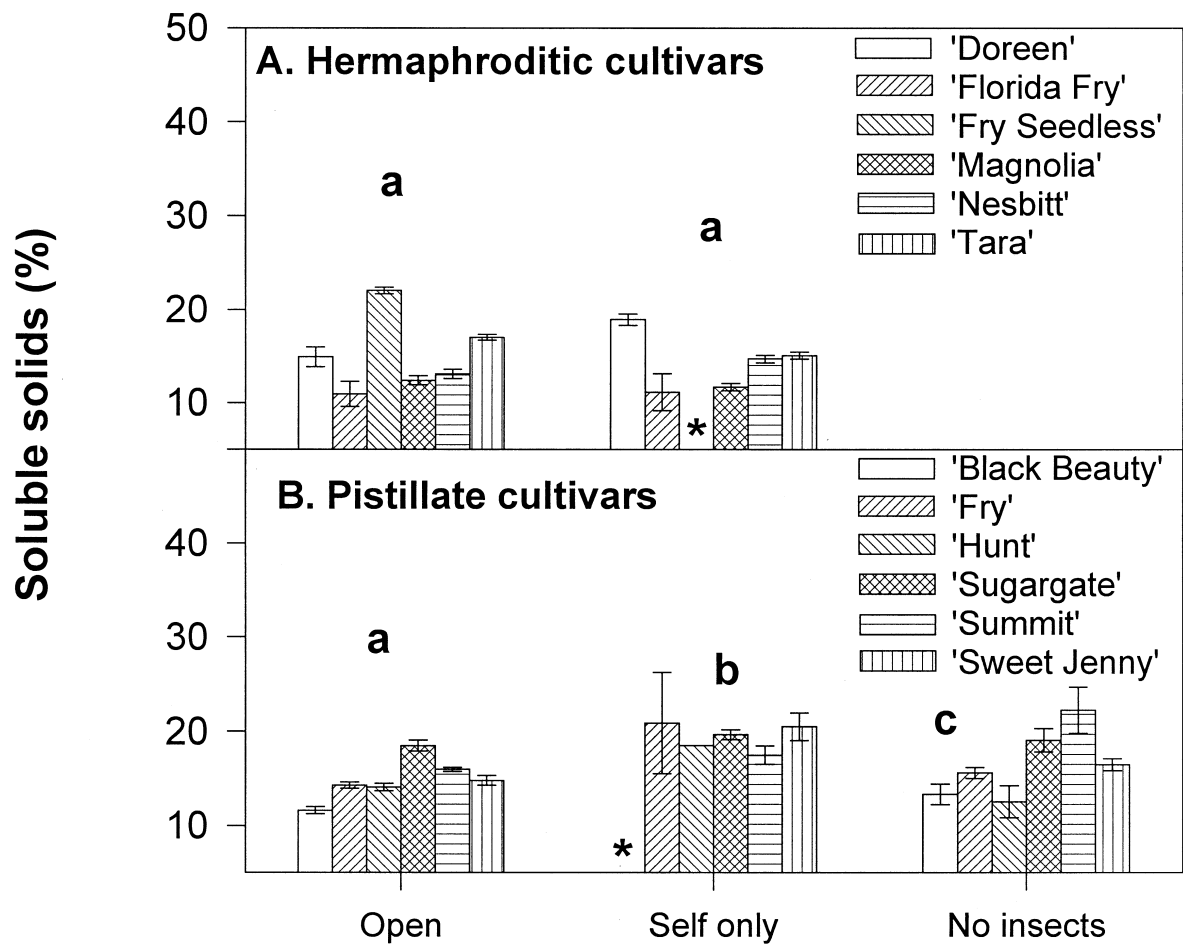

Fig. 5. Effects of open-pollination, self-pollination (self only), and wind- plus self-pollination (no insects) on soluble solids of muscadine grapes. Bars represent mean percentage of soluble solids $\left({ }^{\circ} \mathrm{Brix}\right) \pm 1 \mathrm{SE}$ for each cultivar. Mean separation for pollination treatments by Tukey's HSD test at $P \leq 0.05$. Pollination mode $\times$ cultivar interactions for both hermaphroditic and pistillate vines were significant at $P \leq 0.0078$. The asterisks indicate that no 'Fry Seedless' or 'Black Beauty' flowers produced fruit when selfed. All other cultivars produced some seeded fruits.

grape, and we will begin to assess the value of supplemental pollinators for improving yield and fruit quality. For the muscadine grape, improper application of pesticides that can harm pollinators could seriously reduce current levels of muscadine grape productivity. grapes. J. Mitchell Soc. Nov.: 120-127.

Faegri, K. and L. Van der Pijl. 1971. The principles of pollination ecology. $2^{\text {nd }}$ ed. Pergamon Press, New York.

Feo Brito, F., A. Martinez, R. Palacios, P. Mur, E. Gomez, P.A. Galindo, J. Borja and J. Martinez. 1999. Rhinoconjunctivitis and asthma caused by vine pollen: A case report. J. Allergy Clin. Immunol. 103:262-266.

Free, J.B. 1970. Insect pollination of crops. Academic Press, New York.

Kalifman, I.A. 1977. Bee pollination and the phenomenon of heterosis in agricultural plants, $\mathrm{p}$. 22-40. In: A.N. Mel'Nichenko (ed.). Pollination of agricultural crops by bees. Min. Agr. USSR, Moscow.

Kearns C.A. and D. Inouye. 1993. Techniques for pollination biologists. Univ. Press of Colorado, Niwot, Colo.

McGregor, S.E. 1976. Insect pollination of cultivated crop plants. U.S. Dept. of Agr., Agr. Res. Serv. Handbook No. 496:1-411.

Mullins, M.G., A. Bouquet, and L.E. Williams. 1992. Biology of the grapevine. Cambridge Univ. Press, New York.

NeSmith, D.S. 1999. Fruit set and berry size of 'Fry' muscadine grape in response to six pollen sources. HortScience 34:355.

Pratt, C. 1971. Reproductive anatomy in cultivated grapes-A review. New York State Agr. Expt. Sta. Paper No. 1819:92-109.

SAS Institute Inc. 1985. SAS user's guide: Statistics $\left(5^{\text {th }}\right.$ ed.). SAS Inst., Cary, N.C.

Soldatov, V.I. 1976. Economic effectiveness of bees as pollinators of agricultural crops, p. 125134. In R.B. Kosin (ed.). Pollination of entomophilous agricultural crops by bees. Amerind Publ. Co., New Delhi, India.

Sokal and Rohlf. 1969. Biometry. Freeman, San Francisco, Calif.

Tkachenko, G.V. 1977. Role of insects in the pollination of grape, p. 372-374. In: A.N Mel'Nichenko (ed.). Pollination of agricultural crops by bees. Min. Agr. USSR, Moscow.

Armstrong, W.D. 1936. New varieties and pollination of muscadine grapes. Proc. Amer. Soc. Hort. Sci. 33:450-452.

Dearing, C. 1938. Muscadine grapes. U.S. Dept. of Agr., Farmers' Bul. 1785:1-37.

Detjen, L.R. 1917. Pollination of the rotundifolia
Winkler, A.J., J.A. Cook, W.M. Kliewer, and L.A Lider. 1974. General viticulture. Univ. Calif. Press, Berkeley. 